\title{
Why Broca's Area Damage Does Not Result in Classical Broca's Aphasia
}

\author{
Alfredo Ardila ${ }^{1 *}$, Byron Bernal $^{2}$ and Monica Rosselli ${ }^{3}$ \\ ${ }^{1}$ Department of Communication Sciences and Disorders, Florida International University, Miami, FL, USA, ${ }^{2}$ Radiology \\ Department/Brain Institute, Nicklaus's Children's Hospital, Miami, FL, USA, ${ }^{3}$ Department of Psychology, Florida Atlantic \\ University, Davie, FL, USA
}

Keywords: Broca's area, Broca aphasia, Broca complex, Broca's area aphasia, fMRI

Traditionally it has been assumed that language production is controlled by Broca's area, corresponding to Brodmann's area (BA) 44 (pars opercularis of the left hemisphere) (e.g., Head, 1926; Luria, 1947/1970; Goldstein, 1948; Hécaen, 1972; Damasio and Geschwind, 1984). Since about some 20 years ago, it has been considered that BA45 (pars triangularis) is also part of the Broca's area (Foundas et al., 1996). Some authors have referred to a more extended language production system; Hagoort $(2005,2006)$ proposed that there is a "Broca's complex," including BA44, BA45, and also BA47. Lemaire et al. (2013) refer to an extended Broca's area; Kadis et al. (2016) to an expressive language network; Bernal et al. (2015) to a Broca's network; and Ardila et al. (2016) proposed a "Broca's complex" including not only left BA44 and BA45, but also BA46, BA47, partially BA6 (mainly its mesial supplementary motor area) and extending subcortically toward the basal ganglia and the thalamus.

During the last years, there has been a significant interest in re-analyzing the function of Broca's area in language (e.g., Hagoort, 2005; Thompson-Schill, 2005; Grodzinky and Amunts, 2006; Burns and Fahy, 2010). Different proposals have been presented including: binding the elements of the language (Hagoort, 2005), selecting information among competing sources (Thompson-Schill,

OPEN ACCESS

Edited by:

Agustin Ibanez, CONICET-FAVALORO-INECO-UAI,

Argentina

Reviewed by:

Marcelo L. Berthier, University of Malaga, Spain Loraine K. Obler,

City University of New York, USA

*Correspondence:

Alfredo Ardila

ardilaa@fiu.edu

Received: 22 January 2016 Accepted: 13 May 2016

Published: 01 June 2016

Citation:

Ardila A, Bernal B and Rosselli M (2016) Why Broca's Area Damage

Does Not Result in Classical Broca's

Aphasia.

Front. Hum. Neurosci. 10:249.

doi: 10.3389/fnhum.2016.00249
2005), generating/extracting action meanings (Fadiga et al., 2006); sequencing motor/expressive elements (Ardila and Bernal, 2007); cognitive control mechanism for the syntactic processing of sentences (Novick et al., 2005); construction of higher parts of the syntactic tree in speech production (Grodzinsky, 2000, 2006); and verbal working memory (Haverkort, 2005). Other authors have suggested that Broca's area subregions might be compatible with the system of prefrontal hierarchical control (Bookheimer, 2002). Koechlin and Jubault (2006) for instance, proposed that the more posterior subregions of Broca's area are preferentially engaged in language tasks based on phonological processing (in which discrete actions must be organized in time), whereas the more anterior regions including BA44, BA45, and BA47 are more precisely involved in tasks based on syntactic and semantic processing, presumably representing a higher organizational hierarchy.

Evidently, the cumulative research on the functions of Broca's area is intriguing but has not given a final answer to what is the fundamental function of Broca's area in language processing.

In the classical aphasia literature it is assumed that damage in the Broca's area is responsible for the clinical manifestations observed in Broca's aphasia (e.g., Head, 1926; Luria, 1947/1970; Goldstein, 1948; Hécaen, 1972; Damasio and Geschwind, 1984). Usually, it is assumed that Broca's aphasia includes two major impairments: apraxia of speech and agrammatism (e.g., Hécaen, 1972; Luria, 1976; Kertesz, 1979; Benson and Ardila, 1996). Only with the introduction of the CT scan did it become evident that the damage restricted to the Broca's area was not enough to produce the "classical" Broca's aphasia; extension to the insula, lower motor cortex, and subjacent subcortical and periventricular white matter is required (Alexander et al., 1990; Benson and Ardila, 1996). The mild language disturbance observed in cases of damage of Broca's areas was named "Broca's area aphasia" or “minor Broca’s aphasia” or "Broca's aphasia type I (Benson and Ardila, 1996). This 

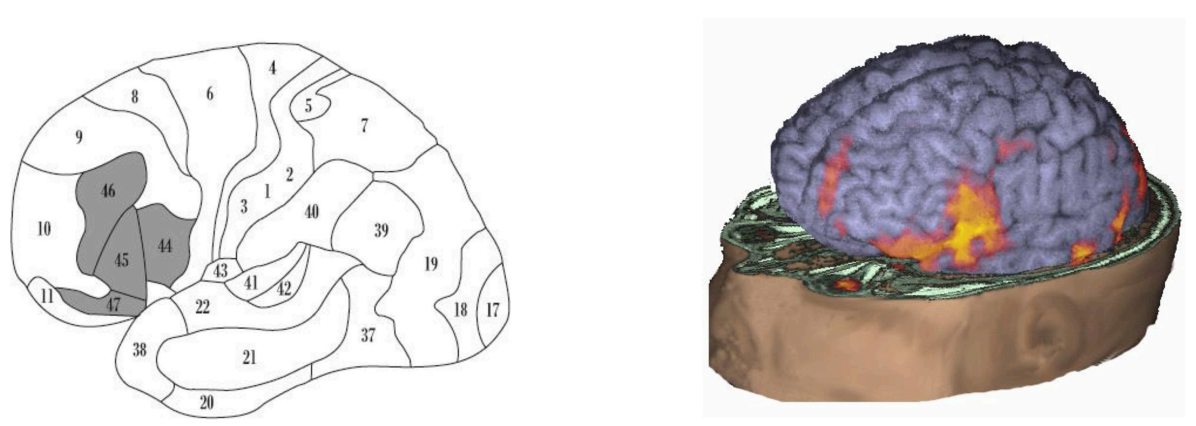

FIGURE 1 | Brain areas involved in language production. (Left panel) "Broca's system" (according to Ardila et al., 2016), including BA44, BA45, BA46, BA47, mesial BA6 (supplementary motor area; not seen) and extending subcortically toward the basal ganglia and the thalamus (not seen). (Right panel) fMRI activation during speaking in a normal adult subject; observed is a wide activation including not only BA44 but also the surrounding areas, extending to the supplementary motor area (courtesy of the Department of Radiology- Nicklaus Children's Hospital).

type of aphasia is characterized by mildly non-fluent speech, relatively short sentences and mild agrammatism. Phonetic deviations, a few phonological paraphasias can be observed (Mohr et al., 1978) and some foreign accent can also be noticed (Ardila et al., 1988). Noteworthy, brain damage restricted to the Broca's area represents an extremely unusual clinical condition. Beginning with Broca, the overwhelming majority of Broca's aphasia patients present an extended brain damage, significantly exceeding the Broca's area (Broca, 1863; Mohr et al., 1978; Naeser and Hayward, 1978; Kertesz, 1979). Dronkers et al. (2007) using high resolution MR imaging studied the brains of the two initial cases of aphasia reported by Broca, Leborgne and Lelong, and found that both patients' lesions extended significantly into medial regions of the brain, in addition to the surface lesions described by Broca. They concluded that Broca's aphasia is associated to large lesions extending beyond the Broca's area.

From the above observations, it can be concluded that Broca's aphasia requires extensive brain lesions. Lesions restricted to Broca's area are associated with just in mild language production defects.

Using direct cortical surface recordings in neurosurgical patients it has been reported that during the cued production of words, a sequence of neural events proceeds from word memories in the temporal lobe to the articulatory movements in the motor cortical motor area. Broca's area plays a monitoring role with reciprocal interactions with temporal and frontal motor brain areas. These results corroborate that Broca's area coordinates the movement of information across extended brain circuits involved in speaking. Consequently, word production

\section{REFERENCES}

Alexander, M. P., Naeser, M. A., and Palumbo, C. (1990). Broca's area aphasias: aphasia after lesions including the frontal operculum. Neurology 40, 353-362. doi: 10.1212/WNL.40.2.353

Ardila, A., and Bernal, B. (2007). What can be localized in the brain? Towards a "factor" theory on brain organization of cognition. Int. J. Neurosci. 117, 935-969. doi: 10.1080/00207450600912222 requires the participation of multiple cortical areas (Flinker et al., 2015).

Functional neuroimaging studies have demonstrated that language production not only activates Broca's area, but also a wide circuit including the surrounding areas (BA46, BA47, and the anterior insula), the supplementary motor areas, and extending subcortically (Figure 1).

If considering BA44 (and BA45) represents only a fragment of the brain system involved in language production, it becomes understandable that restricted damage in this area results in just a partial ("minor") Broca's aphasia. During speech production, Broca's area is not the only area that becomes active, but there is an extended brain system including not only cortical but also subcortical areas. Classical Broca's area represents just a step in the brain language production system. Noteworthy, damage in other areas of this language production system (BA46, BA47, supplementary motor area, and subcortical areas-basal ganglia and thalamus) can also result in language production deficits (Papathanasiou et al., 2012), though with some idiosyncratic characteristics.

In conclusion we propose that lesions confined to the canonical Broca’s area do not result in classical Broca’s aphasia due to the large functional connectivity of this area with adjacent frontal and subcortical areas.

\section{AUTHOR CONTRIBUTIONS}

AA, Primary writing; BB, fMRI analyses; MR, literature review; final writing. areas? A review of Brodmann areas involvement in language. Arch. Clin. Neuropsychol. 31, 112-122. doi: 10.1093/arclin/acv081

Ardila, A., Rosselli, M., and Ardila, O. (1988). Foreign accent: an aphasic epiphenomenon? Aphasiology 2, 493-499. doi: 10.1080/026870388082 48955

Benson, D. F., and Ardila, A. (1996). Aphasia: A clinical perspective. New York, NY: Oxford University Press. 
Bernal, B., Ardila, A., and Rosselli, M. (2015). Broca's area network in language function: a pooling-data connectivity study. Front. Psychol. 6:687. doi: 10.3389/fpsyg.2015.00687

Bookheimer, S. (2002). Functional MRI of language: new approaches to understanding the cortical organization of semantic processing. Annu. Rev. Neurosci. 25, 151-188. doi: 10.1146/annurev.neuro.25.112701.142946

Broca, P. (1863). Localization des fonctions crbrales: siege du langage articulé. Bull. Soc. d'Anthropol. 4, 200-203.

Burns, M. S., and Fahy, J. (2010). Broca's area: rethinking classical concepts from a neuroscience perspective. Top. Stroke Rehabil. 17, 401-410. doi: 10.1310/tsr1706-401

Damasio, A. R., and Geschwind, N. (1984). The neural basis of language. Annu. Rev. Neurosci. 7, 127-147. doi: 10.1146/annurev.ne.07.030184.001015

Dronkers, N. F., Plaisant, O., Iba-Zizen, M. T., and Cabanis, E. A. (2007). Paul Broca's historic cases: high resolution MR imaging of the brains of Leborgne and Lelong. Brain 130, 1432-1441. doi: 10.1093/brain/awm042

Fadiga, L., Craighero, L., and Roy, A. (2006). "Broca's region: a speech area?" in Broca's Region, eds Y. Grodzinky and K. Amunts (New York, NY: Oxford University Press), 137-152. doi: 10.1093/acprof:oso/9780195177640. 003.0009

Flinker, A., Korzeniewska, A., Shestyuk, A. Y., Franaszczuk, P. J., Dronkers, N. F., Knight, R. T., et al. (2015). Redefining the role of Broca's area in speech. Proc. Natl. Acad. Sci. U.S.A. 112, 2871-2875. doi: 10.1073/pnas. 1414491112

Foundas, A. L., Leonard, C. M., Gilmore, R. L., Fennell, E. B., and Heilman, K. M. (1996). Pars triangularis asymmetry and language dominance. Proc. Natl. Acad. Sci. U.S.A. 93, 719-722. doi: 10.1073/pnas.93.2.719

Goldstein, K. (1948). Language and Language Disturbances. New York, NY: Grune and Stratton.

Grodzinky, Y., and Amunts, K. (eds.). (2006). Broca's Region. New York, NY: Oxford University Press. doi: 10.1093/acprof:oso/9780195177640.001.0001

Grodzinsky, Y. (2000). The neurology of syntax: language use without Broca's area. Behav. Brain Sci. 23, 1-21. doi: 10.1017/S0140525X00002399

Grodzinsky, Y. (2006). The language faculty, Broca's region, and the mirror system. Cortex 42, 464-468. doi: 10.1016/S0010-9452(08)70378-2

Hagoort, P. (2005). "Broca's complex as the unification space for language," in Twenty-first Century Psycholinguistics: Four Cornerstones, ed A. Cutler (Mahwah, NJ: Lawrence Erlbaum Associates), 157-172.

Hagoort, P. (2006). “On Broca, brain and binding," in Broca's Region, eds Y. Grodzinsky and K. Amunts (Oxford, UK: Oxford University Press), 242-253. doi: 10.1093/acprof:oso/9780195177640.003.0015

Haverkort, M. (2005). "Linguistic representation and language use in aphasia," in Twenty-first Century Psycholinguistics: Four Cornerstones. ed A. Cutler (Mahwah, NJ: Lawrence ErlbaumAssociates Inc.), 57-68.

Head, H. (1926). Aphasia and Kindred Disorders of Speech. London: Cambridge University Press.
Hécaen, H. (1972). Introduction a la Neuropsychologie. Paris: Larousse.

Kadis, D. S., Dimitrijevic, A., Toro-Serey, C. A., Smith, M. L., and Holland, S. K. (2016). Characterizing information flux within the distributed pediatric expressive language network: a core region mapped through fMRIconstrained MEG effective connectivity analyses. Brain Connect. 6, 76-83. doi: 10.1089/brain.2015.0374

Kertesz, A. (1979). Aphasia and Associated Disorders: Taxonomy, Localization, and Recovery. Austin, TX: Holt Rinehart \& Winston.

Koechlin, E., and Jubault, T. (2006). Broca's area and the hierarchical organization of human behavior. Neuron 50, 963-974. doi: 10.1016/j.neuron.2006.05.017

Lemaire, J. J., Golby, A., Wells, W. M. III, Pujol, S., Tie, Y., Rigolo, L., et al. (2013). Extended Broca's area in the functional connectome of language in adults: combined cortical and subcortical single-subject analysis using fMRI and DTI tractography. Brain Topogr. 26, 428-441. doi: 10.1007/s10548-012-0257-7

Luria, A. R. (1947/1970). Traumatic Aphasia: Its Syndromes, Psychology and Treatment, Vol. 5. Amsterdam: Walter de Gruyter.

Luria, A. R. (1976). Basic Problems of Neurolinguistics, Vol. 73. Amsterdam: Walter de Gruyte. doi: 10.1515/9783110800159

Mohr, J. P., Pessin, M. S., Finkelstein, S., Funkenstein, H. H., Duncan, G. W., and Davis, K. R. (1978). Broca aphasia: pathologic and clinical. Neurology 28, 311-324. doi: 10.1212/WNL.28.4.311

Naeser, M. A., and Hayward, R. W. (1978). Lesion localization in aphasia with cranial computed tomography and the Boston Diagnostic Aphasia Exam. Neurology 28, 545-545. doi: 10.1212/WNL.28.6.545

Novick, J. M., Trueswell, J. C., and Thompson, S. L. (2005). Cognitive control and parsing: reexamining the role of Broca's area in sentence comprehension. Cogni. Affect. Behav. Neurosci. 5, 263-281. doi: 10.3758/CABN.5.3.263

Papathanasiou, I., Coppens, P., and Potagas, C. (2012). Aphasia and Related Neurogenic Communication Disorders. Burlington, MA: Jones \& Bartlett Publishers.

Thompson-Schill, S. L. (2005). "Dissecting the language organ: a new look at the role of Broca's area in language processing," in Twenty-first Century Psycholinguistics: Four cornerstones, ed A. Cutler (Mahwah, NJ: Lawrence Erlbaum Associates Inc.), 173-190.

Conflict of Interest Statement: The authors declare that the research was conducted in the absence of any commercial or financial relationships that could be construed as a potential conflict of interest.

Copyright (c) 2016 Ardila, Bernal and Rosselli. This is an open-access article distributed under the terms of the Creative Commons Attribution License (CC BY). The use, distribution or reproduction in other forums is permitted, provided the original author(s) or licensor are credited and that the original publication in this journal is cited, in accordance with accepted academic practice. No use, distribution or reproduction is permitted which does not comply with these terms. 